\title{
EDITORIAL
}

\section{Pain and Rheumatology: Thinking Outside the Joint}

\author{
Daniel J. Clauw ${ }^{1}$ and James Witter ${ }^{2}$
}

Osteoarthritis (OA) of the hip and knee is a common chronic pain condition, the impact of which will continue to increase as the population ages. OA is typically diagnosed when an individual presents for medical attention with pain in the hip or knee and a radiograph is obtained that documents degenerative changes consistent with OA. Pain in OA has been classically attributed to joint damage, and nearly all therapies have been aimed at treating or curing the pain derived from this "organ," including exercise, topical analgesics, oral nonsteroidal antiinflammatory drugs (NSAIDs) and opioids, direct injections, and eventually joint replacement.

Clearly, the limited or short-term efficacy of most available therapies (1) and the observation that even replacing the joint does not always cure the pain (2) suggest that factors other than joint pathology must be partially responsible for the pain and dysfunction experienced by patients with chronic OA pain. If damage to the cartilage and bone is the "disease" called OA, then the magnitude of damage to or inflammation in one or both of these structures should predict clinical symptoms. However, population-based studies suggest that there is a significant disparity between the degree of peripheral damage noted on radiographs and the pain and functional limitations that patients with this condition experience. The most dramatic evidence of this is that $30-60 \%$ of individuals with moderate to severe radiographic changes of $\mathrm{OA}$ are completely asymptomatic, and $\sim 10 \%$ of individuals with moderate to severe knee pain have normal radiographs $(3,4)$.

\footnotetext{
${ }^{1}$ Daniel J. Clauw, MD: University of Michigan, Ann Arbor; ${ }^{2}$ James Witter, MD, PhD: National Institute of Arthritis and Musculoskeletal and Skin Diseases, NIH, Bethesda, Maryland.

Dr. Clauw has received consulting fees, speaking fees, and/or honoraria from Wyeth and UCB (less than \$10,000 each) and from Eli Lilly, Forest, Cypress Biosciences, and Pfizer (more than $\$ 10,000$ each).

Address correspondence and reprint requests to Daniel J. Clauw, MD, Professor of Anesthesiology and Medicine, University of Michigan, 24 Frank Lloyd Wright Drive, PO Box 385, Ann Arbor MI 48106. E-mail: dclauw@umich.edu.

Submitted for publication November 14, 2008; accepted November 17,2008 .
}

Not surprisingly, the disparity between radiographic features and symptoms has led investigators to explore the notion that psychological factors are responsible for this discordance. Again, these studies have suggested that psychological factors such as anxiety and depression do account for some of this variance in pain and other symptoms, but to only a small degree $(5,6)$.

In this issue of Arthritis \& Rheumatism, van Meurs and colleagues explore a new line of research in hip OA that suggests that some of the variance between pain and peripheral damage can be accounted for by a gene involved in modulating pain sensitivity, as well as several other traits. They showed that in a large OA database in which there was the typical poor overall relationship between radiographic changes and pain levels, individuals with the $158 \mathrm{Met}$ variant of COMT had an almost 3 -fold higher risk $(P=0.02)$ of hip pain as compared with carriers of the Val/Val genotype. As noted by van Meurs et al, this effect was fully driven by the female carriers. Female carriers of the $158 \mathrm{Val}$ allele were 4.9-fold more likely to have pain $(95 \%$ confidence interval 1.6-14.8, $P=0.005$ ), while radiographic damage to the hip was present in both genotype groups.

Although this effect is very strong, it is not surprising to those involved in the study of pain. Pain is ultimately experienced in the brain, not in the peripheral tissues, and the function of pain processing systems throughout the body markedly influences who has pain and how much pain an individual experiences. Just as we know that there is tremendous variability in pain sensitivity between strains of rodents, there similarly is great variability in pain sensitivity among humans (7). In the past decade, there has been an explosion of knowledge regarding the genetics of pain. Within the past few years alone, we have learned that genes such as those responsible for catechol-O-methyltranferase (COMT), GTP cyclohydrolase $1(\mathrm{GCH} 1)$, and the voltage-gated sodium channel Nav1.9 exert significant control in human pain perception (8-11). Because of this, many investigators involved in the study of pain now believe that chronic pain is itself a disease, and the location of the body 
where it arises may not be as relevant as an individual's genetically determined pain sensitivity, combined with neuroplastic changes that can occur in the central nervous system (CNS) that lead to augmented pain transmission.

These heightened states of pain sensitivity are termed hyperalgesia (increased pain in response to normally painful stimuli) and/or allodynia (pain in response to normally nonpainful stimuli). These states often can be triggered by an initial peripheral injury or inflammatory process and may be regional or widespread. These phenomena have been noted to occur in nearly all individuals with conditions such as fibromyalgia and subsets of individuals with numerous other chronic pain conditions, such as OA, idiopathic low back pain, and rheumatoid arthritis (12-15). Hyperalgesia and allodynia are not just noted by patient self-report: their existence has been repeatedly corroborated by functional neuroimaging studies demonstrating objective evidence of this increased pain sensitivity $(15,16)$.

The COMT story is worth expanding upon because of its clear relevance to human pain perception. Zubieta et al first showed that the COMT Val158Met polymorphism was responsible for differential pain sensitivity in humans, working in part by modulating the endogenous $\mu$-opioid system (17). The same Val158Met polymorphism is weakly associated with several psychiatric disorders (18). Recently, Diatchenko and colleagues at the University of North Carolina carried out a series of elegant studies that used haplotype analyses to identify 3 subsets of individuals based on the findings in 4 COMT single-nucleotide polymorphisms (SNPs), termed low pain sensitive (LPS), average pain sensitive (APS), and high pain sensitive (HPS) groups (10). Those investigators have gone on to show that these subgroups are highly predictive of pain sensitivity in a variety of different experimental pain-inducing tasks (19). Moreover, in a prospective study, they showed that when 240 pain-free individuals were phenotyped at baseline and then followed up for 3 years to determine in whom temporomandibular joint (TMJ) disorder would develop, individuals in the HPS group were 3 times as likely as the others to develop TMJ disorder (10). Similarly, their studies in rodents showed that the LPS haplotype produced much higher levels of COMT enzymatic activity when compared with the APS or HPS haplotype, and that inhibition of COMT resulted in a profound increase in pain sensitivity in these animals. Finally, they showed that when these synonymously coding SNPs (which heretofore would have been considered "junk" SNPs) were combined into haplotypes, each led to a different RNA structure with markedly different activity (20).

The differential effect of COMT in male and female patients noted by van Meurs et al is also not surprising given what is known about COMT. COMT is inducible by estrogen and has been shown to be partly responsible for sex differences in several different "phenotypic" characteristics of women and men, including pain sensitivity (21). Because these types of genetic factors may play a strong role in determining an individual's experience with pain, it is equally as likely that genetic and epigenetic factors also play key roles in patient-reported outcomes in most rheumatic diseases and may help account for sex differences noted in many rheumatologic disorders.

The findings regarding COMT reported by van Meurs et al are not the only data that suggest that catecholaminergic function might be important in leading to the pain of OA. Clinical trials have shown that classes of drugs that are thought to be acting in part via catecholaminergic mechanisms, such as tricyclics as well as serotonin/norepineprine reuptake inhibitors, can be effective in treating OA as well as a number of other chronic musculoskeletal pain syndromes $(22,23)$. The postulated mechanism of action of these drugs is that they increase serotonergic/noradrenergic activity in descending analgesic pathways. Attenuated descending analgesic activity, which is but one potential mechanism for the hyperalgesia/allodynia seen in patients with chronic pain states, has been noted in many chronic pain syndromes including OA $(14,24)$. The effect sizes and the overall safety profile of these CNS-acting drugs may actually be superior to those seen with more commonly used treatments for OA such as NSAIDs, yet we rarely consider using these medications when treating OA or other musculoskeletal pain syndromes.

$\mathrm{OA}$ is not likely to be the only rheumatologic disorder in which the discordance between peripheral inflammation and/or damage might be attributable to "central" factors. In systemic lupus erythematosus (SLE), for example, neither the degree of inflammation nor the degree of damage is highly associated with pain, fatigue, function, or other symptoms of SLE (25-27). Instead, the presence or absence of comorbid fibromyalgia (which occurs in $\sim 20 \%$ of patients with SLE as well as those with other autoimmune disorders) is the largest predictor of pain, fatigue, and function in patients with SLE $(28,29)$. In fact, Wolfe and Rasker (30) have shown that across all rheumatic diseases, the symptom intensity scale score is a potent predictor of functional status and pain severity regardless of the underlying rheumatologic 
disorder. Furthermore, these scores are associated with more severe medical illness, greater mortality, and increased sociodemographic disadvantage (30). The symptom intensity score is likely a simple measure of the pain and/or sensory amplification that can occur in isolation (e.g., fibromyalgia) or accompanying any chronic pain state, and we are now beginning to understand the "neurobiology" of sensory systems.

Thus, it is time for us to begin to "think outside the joint" when it comes to pain in rheumatic diseases. Within our field, we continue to focus most of our research and clinical efforts on the peripheral structures, even though these factors are, at best, modest predictors of pain and functional disability across all rheumatologic disorders. In fact, there is no medical condition in which the degree of peripheral damage or inflammation accurately predicts the amount of pain an individual will experience or how the patient will functionally respond to that pain. Pain and other symptoms occur in the brain, not the joint.

The tremendous advances in the science of pain provide a wonderful opportunity for rheumatologists to better understand our patients' pain, which is particularly important, because this is often their chief complaint. It will always be important for rheumatologists and our trainees to understand how mechanisms of disease impact the structure of peripheral organs such as kidneys and joints, but we also need to understand mechanisms that might impact pain transmission and the ultimate patient experience of pain. Rheumatologists have an opportunity to learn and then teach clinical and research techniques that would be likely to help bridge the gap between inflammation and structure in the peripheral tissues and the pain, other somatic symptoms, and dysfunction experienced by our patients.

What the van Meurs report reminds us is that the era of evidence-based, individualized analgesia in the rheumatic diseases is beginning to take shape. Identifying successful treatment and eventual cures for chronic pain will require carefully designed studies that test novel hypotheses about how genetic/epigenetic factors interact with environmental risk factors and therapeutics (e.g., drugs, biologic agents, devices, vaccines, nonpharmacologic therapies) in humans and animal models. Results of these types of studies, using state-of-the art pain assessment tools and techniques along with biomarkers, will help shape the way rheumatologists are trained and subsequently treat their patients. Team science needs to be translated to team pain management, in order to maximize the benefits and minimize the risks of effective and meaningful analgesia in rheumatology, now and in the future.

\section{REFERENCES}

1. Bjordal JM, Klovning A, Ljunggren AE, Slordal L. Short-term efficacy of pharmacotherapeutic interventions in osteoarthritic knee pain: a meta-analysis of randomised placebo-controlled trials. Eur J Pain 2007;11:125-38.

2. Kennedy LG, Newman JH, Ackroyd CE, Dieppe PA. When should we do knee replacements? Knee 2003;10:161-6.

3. Creamer P, Keen M, Zananiri F, Waterton JC, Maciewicz RA, Oliver $\mathrm{C}$, et al. Quantitative magnetic resonance imaging of the knee: a method of measuring response to intra-articular treatments. Ann Rheum Dis 1997;56:378-81.

4. Hannan MT, Felson DT, Pincus T. Analysis of the discordance between radiographic changes and knee pain in osteoarthritis of the knee. J Rheumatol 2000;27:1513-7.

5. Creamer P, Hochberg MC. The relationship between psychosocial variables and pain reporting in osteoarthritis of the knee. Arthritis Care Res 1998;11:60-5.

6. Creamer P, Lethbridge-Cejku M, Costa P, Tobin JD, Herbst JH, Hochberg MC. The relationship of anxiety and depression with self-reported knee pain in the community: data from the Baltimore Longitudinal Study of Aging. Arthritis Care Res 1999;12:3-7.

7. Mogil JS, Yu L, Basbaum AI. Pain genes? Natural variation and transgenic mutants. Annu Rev Neurosci 2000;23:777-811.

8. Tegeder I, Costigan M, Griffin RS, Abele A, Belfer I, Schmidt H, et al. GTP cyclohydrolase and tetrahydrobiopterin regulate pain sensitivity and persistence. Nat Med 2006;12:1269-77.

9. Amaya F, Wang H, Costigan M, Allchorne AJ, Hatcher JP, Egerton $\mathrm{J}$, et al. The voltage-gated sodium channel $\mathrm{Na}(\mathrm{v}) 1.9$ is an effector of peripheral inflammatory pain hypersensitivity. J Neurosci 2006;26:12852-60.

10. Diatchenko L, Slade GD, Nackley AG, Bhalang K, Sigurdsson A, Belfer I, et al. Genetic basis for individual variations in pain perception and the development of a chronic pain condition. Hum Mol Genet 2005;14:135-43.

11. Diatchenko L, Nackley AG, Tchivileva IE, Shabalina SA, Maixner W. Genetic architecture of human pain perception. Trends Genet 2007;23:605-13.

12. Yunus MB. Towards a model of pathophysiology of fibromyalgia: aberrant central pain mechanisms with peripheral modulation. J Rheumatol 1992;19:846-50.

13. Williams DA, Farrell MJ, Cunningham J, Gracely RH, Ambrose $\mathrm{K}$, Cupps $\mathrm{T}$, et al. Knee pain and radiographic osteoarthritis interact in the prediction of levels of self-reported disability. Arthritis Rheum 2004;51:558-61.

14. Kosek E, Ordeberg G. Lack of pressure pain modulation by heterotopic noxious conditioning stimulation in patients with painful osteoarthritis before, but not following, surgical pain relief. Pain 2000;88:69-78.

15. Giesecke T, Gracely RH, Grant M, Nachemson A, Petzke F, Williams D, et al. Evidence of augmented central pain processing in idiopathic chronic low back pain. Arthritis Rheum 2004;50:613-23.

16. Gracely RH, Petzke F, Wolf JM, Clauw DJ. Functional magnetic resonance imaging evidence of augmented pain processing in fibromyalgia. Arthritis Rheum 2002;46:1333-43.

17. Zubieta JK, Heitzeg MM, Smith YR, Bueller JA, Xu K, Xu Y, et al. COMT val158met genotype affects mu-opioid neurotransmitter responses to a pain stressor. Science 2003;299:1240-3.

18. Hosak L. Role of the COMT gene Val158Met polymorphism in mental disorders: a review. Eur Psychiatry 2007;22:276-81.

19. Diatchenko L, Nackley AG, Slade GD, Bhalang K, Belfer I, Max MB, et al. Catechol-O-methyltransferase gene polymorphisms are associated with multiple pain-evoking stimuli. Pain 2006;125:216-24. 
20. Nackley AG, Shabalina SA, Tchivileva IE, Satterfield K, Korchynskyi O, Makarov SS, et al. Human catechol-O-methyltransferase haplotypes modulate protein expression by altering mRNA secondary structure. Science 2006;314:1930-3.

21. Harrison PJ, Tunbridge EM. Catechol-O-Methyltransferase (COMT): a gene contributing to sex differences in brain function, and to sexual dimorphism in the predisposition to psychiatric disorders. Neuropsychopharmacology 2008;33:3037-45.

22. Fishbain D. Evidence-based data on pain relief with antidepressants. Ann Med 2000;32:305-16.

23. Russell IJ, Mease PJ, Smith TR, Kajdasz DK, Wohlreich MM, Detke MJ, et al. Efficacy and safety of duloxetine for treatment of fibromyalgia in patients with or without major depressive disorder: results from a 6-month, randomized, double-blind, placebo-controlled, fixed-dose trial. Pain 2008;136:432-44.

24. Clauw DJ. Pharmacotherapy for patients with fibromyalgia. J Clin Psychiatry 2008;69 Suppl 2:25-9.
25. Urowitz MB, Gladman DD. Measures of disease activity and damage in SLE. Baillieres Clin Rheumatol 1998;12:405-13.

26. Wang B, Gladman DD, Urowitz MB. Fatigue in lupus is not correlated with disease activity. J Rheumatol 1998;25:892-5.

27. Neville C, Clarke AE, Joseph L, Belisle P, Ferland D, Fortin PR. Learning from discordance in patient and physician global assessments of systemic lupus erythematosus disease activity. J Rheumatol 2000;27:675-9.

28. Gladman DD, Urowitz MB, Gough J, MacKinnon A. Fibromyalgia is a major contributor to quality of life in lupus. $\mathrm{J}$ Rheumatol 1997;24:2145-8.

29. Clauw DJ, Katz P. The overlap between fibromyalgia and inflammatory rheumatic diseases: when and why does it occur? J Clin Rheumatol 1995;1:335-41.

30. Wolfe F, Rasker JJ. The Symptom Intensity Scale, fibromyalgia, and the meaning of fibromyalgia-like symptoms. J Rheumatol 2006;33:2291-9. 